Volume 8. No. 9, September 2020

International Journal of Emerging Trends in Engineering Research

Available Online at http://www.warse.org/IJETER/static/pdf/file/ijeter120892020.pdf https://doi.org/10.30534/ijeter/2020/120892020

\title{
Testing the hardness of materials by Brinell and Rockwell methods
}

\author{
Olga I. Vaganova ${ }^{1}$, LyubovI.Kutepova ${ }^{2}$, Zhanna V. Smirnova ${ }^{3}$,Anna V. Lapshova ${ }^{4}$,Elena A. Chelnokova \\ ${ }^{1}$ Minin Nizhny Novgorod State Pedagogical University, Nizhny Novgorod, Russia, vaganova_o@rambler.ru \\ ${ }^{2}$ Minin Nizhny Novgorod State Pedagogical University, Nizhny Novgorod, Russia, lubovkutepova@mail.ru \\ ${ }^{3}$ Minin Nizhny Novgorod State Pedagogical University, Nizhny Novgorod, Russia, z.v.smirnova@mininuniver.ru \\ ${ }^{4}$ Minin Nizhny Novgorod State Pedagogical University, Nizhny Novgorod, Russia, lapshova_av@mininuniver.ru \\ ${ }^{5}$ Minin Nizhny Novgorod State Pedagogical University, Nizhny Novgorod, Russia, chelnelena@gmail.com
}

\begin{abstract}
Quality control of metals is a significant process in any industry. To improve the quality of metals, Brinell and Rockwell methods are used as one of the most effective. The purpose of the article is to conduct research on soft steel and non-ferrous alloys using Brinell and Rockwell methods. The most common method is considered to be indentation of the indenter. These methods are widely used, including for research purposes.
\end{abstract}

Key words: hardness of materials, Brinell method, Rockwell method, steel, non-ferrous metal.

\section{INTRODUCTION}

Quality control of metals is a significant process in any industry [1]. Devices for conducting strength tests are quite simple, they can be described as high-performance, can be used directly in the workplace. At the same time, high qualification of employees is not required [2].

The Rockwell method is widely used because it makes it possible to test soft, hard and thin materials. Rockwell hardness values can be converted to Brinell values and Vice versa. Special tables are used for this purpose [3].

The Rockwell hardness is the difference calculated between the depth of the print at maximum load and its depth at preload [4].

This method, due to the fact that the prints of the cone or ball are extremely small, allows you to test the finished parts without damage [5]. The study is not labor-intensive and does not take much time, since the hardness number is read directly on the scale [6].

There are several ways to determine the hardness:

- static [7];

- dynamic [8];

- kinetic [9].

Static methods are the most common. With them, the load is applied to the indenter gradually. The Brinell measurement method is regulated by GOST 9012. The Rockwell hardness test method is regulated by GOST 9013 [10].
The article presents a study of mild steel and non-ferrous alloys.

\section{THEORETICALFRAMEWORK}

Scientists consider the concept of "hardness" as the ability of materials to resist plastic deformation when exposed to contact in the surface layer by a more solid body, which is called an indenter.

Hardness can be measured in three ranges:

- macro;

- micro;

- nano [11].

The macro range (hardness) sets the load rules for indentors from $2 \mathrm{H}$ to $30 \mathrm{kH}[12]$.

Micro range is micro hardness. And it regulates the amount of load on the indenter up to $2 \mathrm{H}$ and the depth of its implementation by $0.2 \mathrm{mkm} \mathrm{[13].}$

The nano range (nanohardness) allows regulating only the depth of indenter insertion, which should be less than 0.2 mkm [14].

The paper considers the methods of Brinell and Rockwell.

The Brinell automatic lever press used in the study is shown in figure 1 (according To G. V. Klevtsov) [15].

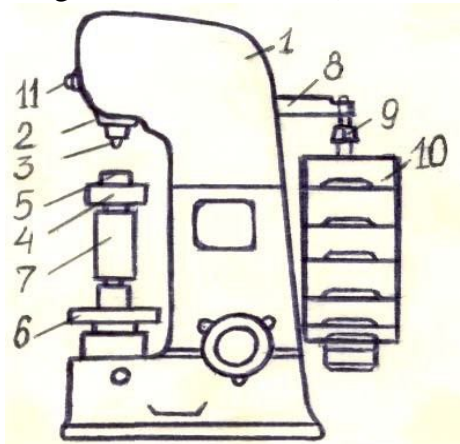

Figure 1: Brinell lever press scheme

It includes the following components:

- frame;

- spindle;

- tip with ball;

- table (for sample installation);

- rotating disk;

- screw; 
Olga I. Vaganova et al., International Journal of Emerging Trends in Engineering Research, 8(9), September 2020, 5651 - 5654

- hardened ball.

- lever;

- suspension;

- indicator light.

The Rockwell device consists of :

- frames;

- spindles;

- indenter's;

- table's;

- flywheel's;

- screw's;

- dial with indicator.

The Rockwell hardness number is an abstract number and is expressed in conventional units.

The Rockwell hardness number is calculated using the formula HRB 130 - e (when measured on the B scale), HRC = 100-e (on the C scale), HRA 100-e.

\section{RESULTSANDDISCUSSION}

The purpose of this work is to test metals using Brinell and Rockwell methods.

The following materials and tools were used for the research:

- automatic Brinell press;

- Rockwell device;

- magnifying glass for measuring the diameter of the print;

- samples from non-heat-treated steel;

samples made of hardened steel;

- samples of non-ferrous metal alloy of various thickness;

- emery sharpener;

- file;

- emery cloth.

The Brinell hardness test was performed by pressing a ball $\mathrm{D}$ (a steel hardened ball with a diameter $\mathrm{d}$ and a depth $\mathrm{h}$ as shown in the figure presented by G. V. Klevtsov) into the test sample under the action of a given load $\mathrm{P}$ for some time [15].

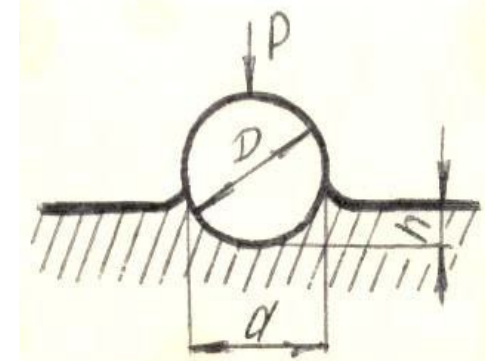

Figure 2: The scheme of hardness test Brinell

After removing the load on the surface of the sample, an imprint (hole) with a diameter $\mathrm{d}$ and a depth $\mathrm{h}$ is obtained.

The Brinell hardness number (HB) as the ratio of the load $\mathrm{P}$ to the surface of the resulting print (ball segment) [15].

$\mathrm{HB}=\mathrm{P} / \mathrm{F}$

The depth of the print is difficult to measure, so the diameter of the print $d$ was measured. The value of $h$ was expressed in terms of the diameter of the ball $\mathrm{D}$ and the print $\mathrm{d}$ [15].

When measuring the hardness of a material using the Brinell method the following rules were taken into account:

- materials with a hardness higher than HB 450/650 kgs $/ \mathrm{mm} 2$ were not used;
- the surface of the test sample is flat and smooth, without any damage;

- samples had a thickness of at least 10 times the depth of the print;

- exposure time under load takes from 10 to 15 seconds for ferrous metals and from 10 to 180 seconds for non-ferrous metals and alloys (depending on the material and its hardness).

Among the restrictions for the Brinell hardness tester is worth highlighting:

- prohibition to measure the hardness of HB parts made of the same material (the same part) using different hardness testers [15];

- the ratio of the applied load and the footprint must be constant [16].

Determining the hardness of the material using the Brinell method used balls with a diameter of: $10 \mathrm{~mm} ; 5 \mathrm{~mm} ; 2.5 \mathrm{~mm}$.

The diameter was chosen depending on the thickness of the test sample (the thicker the sample, the smaller the diameter) [17]. The load $P$ was selected depending on the hardness of the material according to the following formula

$\mathrm{P}=\mathrm{KD}^{2}$

$\mathrm{K}$ is a coefficient that depends on the degree of hardness of the tested material [18].

«For the first approximation, the following were accepted:

- for steel and cast iron $(\mathrm{K}=30)$;

- for copper and copper alloys $(\mathrm{K}=10)$;

- for soft metals, including magnesium, aluminum, lead, tin and some alloys based on them $(\mathrm{K}=2.5) »[18]$.

In order to select the exact ball diameter and load (depending on the thickness and hardness of the test material), the study used the following data presented in table 1 .

Table 1: Table for selection of ball diameter and load

\begin{tabular}{|l|c|c|l|c|c|c|}
\hline Material & HB & $\begin{array}{c}\text { Min } \\
\text { sampl } \\
\text { ethick } \\
\text { ness }\end{array}$ & $\begin{array}{l}\mathrm{P}= \\
\mathrm{KD}\end{array}$ & $\begin{array}{l}\mathrm{D} \\
(\mathrm{mm})\end{array}$ & $\mathrm{P}, \mathrm{H}$ & $\mathrm{t}$ \\
& & & & \\
\hline Blackmet & 140 & $6-3$ & $300 \mathrm{D}$ & 10 & 30000 & 10 \\
als & -45 & $4-2$ & & 5 & 7500 & \\
& 0 & $<2$ & & 2,5 & 1875 & \\
\cline { 2 - 7 } & $<14$ & $>6$ & $100 \mathrm{D}$ & 10 & 10000 & 10 \\
& 0 & $6-3$ & & 5 & 2500 & \\
& & $<3$ & & 2,5 & 625 & \\
\hline Non-ferr & $>$ & $6-3$ & $300 \mathrm{D}$ & 10 & 30000 & 30 \\
ousmetal & 130 & $4-2$ & & 5 & 7500 & \\
s & 0 & $<2$ & & 2,5 & 1875 & \\
\cline { 2 - 7 } & 350 & $9-3$ & $100 \mathrm{D}$ & 10 & 10000 & 30 \\
& -13 & $6-3$ & & 5 & 2500 & \\
& 00 & $<3$ & & 2,5 & 625 & \\
\hline & $80-$ & $>6$ & $25 \mathrm{D}$ & 10 & 2500 & 60 \\
& 350 & $6-3$ & & 5 & 625 & \\
& & $<3$ & & 2,5 & 156 & \\
\hline
\end{tabular}

$\mathrm{t}$ - is the holding time under load.

In order to avoid permanent deformation of the hardened balls, it is necessary that the hardness of the test materials does not exceed HB 450. 
Olga I. Vaganova et al., International Journal of Emerging Trends in Engineering Research, 8(9), September 2020, 5651 - 5654

Before testing, the surface of the sample (into which the ball is pressed) was treated with an emery stone to give it evenness and smoothness (so that there was no scale or other defects).

Note that the sample is not heated more than $100-150^{\circ} \mathrm{C}$ during processing [9].

The accuracy of the resulting print depends on the correct preparation of the sample surface (samples were obtained where the edges are clearly visible for measurements).

To prepare the Brinell press for the test the following actions were performed:

- loads corresponding to the load selected for testing were installed on the suspension;

- the tip with the ball was inserted into the spindle and strengthened;

- the test sample was placed on the table;

- the table was raised by rotating the disk clockwise;

- the electric motor was switched on;

- after automatically stopping the rotation of the electric motor, the table was lowered and the sample with the resulting fingerprint was removed from it;

- measured the diameter of the resulting print;

- then the hardness of the sample material was determined.

A special magnifying glass was used to measure the resulting print (the measurement was made in two directions).

The print diameter is calculated as the arithmetic mean of two dimensions. The magnifier has a scale with a division price of $0.05 \mathrm{~mm}$. With the lower part of the support, the magnifier is pressed tightly against the surface of the test sample (above the print).

The reading on the magnifying glass scale is shown in figure 3 (presented by G. V. Klevtsov) [9].

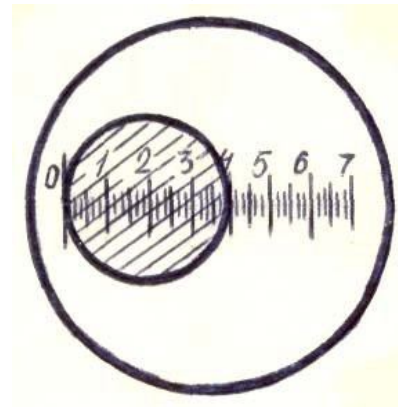

Figure 3: Counting on the magnifying glass scale

The division of the scale with which the opposite edge of the print coincides was calculated. This count corresponds to the size of the print diameter. To calculate the hardness, a special table was used, which gives the translation of the print diameter into the hardness number HB.The Rockwell hardness test was performed by pressing a diamond cone (hard alloy) «with an angle of $120^{\circ}$ and a hardened steel ball with a diameter of $1.588 \mathrm{~mm}$ into the test piece.

The ball and cone were pressed into the test sample under the action of two consecutive applied loads» [19]: pre-P0; main $\mathrm{P} 1 . \mathrm{P}=\mathrm{P}_{0}+\mathrm{P}_{1}$.

The preload in both cases is $100 \mathrm{H}$. The main load P1 and the total $\mathrm{P}$ and type of indenter depend on the hardness of the test material.The choice of the load and indenter for the study was carried out according to table 2 (according To G. V. Klevtsov).
Table 2: Selecting the indenter load for testing

\begin{tabular}{|l|l|l|l|l|l|}
\hline Material & $\begin{array}{l}\text { Indentert } \\
\text { ype }\end{array}$ & $\begin{array}{l}\mathrm{P}_{0 .} \\
\mathrm{H}\end{array}$ & $\mathrm{P}_{1, \mathrm{H}}$ & $\begin{array}{l}\mathrm{P}, \\
\mathrm{H}\end{array}$ & $\begin{array}{l}\text { Measure } \\
\text { mentlimi } \\
\mathrm{t}\end{array}$ \\
\hline $\begin{array}{l}\text { Solidmater } \\
\text { ials }\end{array}$ & $\begin{array}{l}\text { Diamond } \\
\text { cone }\end{array}$ & 100 & 500 & 600 & $70-85$ \\
\hline Mildsteel & Steelball & 100 & 9000 & 1000 & $25-100$ \\
\hline $\begin{array}{l}\text { Heattreate } \\
\text { dsteels }\end{array}$ & $\begin{array}{l}\text { Diamond } \\
\text { cone }\end{array}$ & 100 & 1400 & 1500 & $20-67$ \\
\hline
\end{tabular}

For the Rockwell hardness number, a value was taken that corresponds to the axial movement of the indenter by 0.002 $\mathrm{mm}$.

Figure 4 shows the scheme for determining the hardness by pressing a diamond cone on the Rockwell device (according To G. V. Klevtsov).

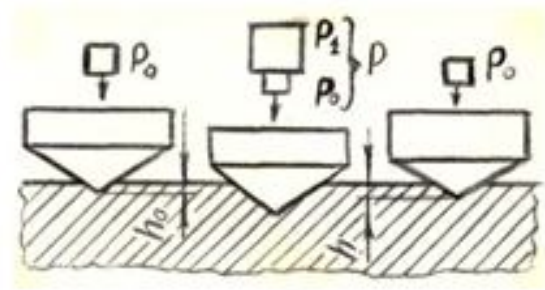

Figure 4: The scheme of hardness test

Rockwell hardness values can be converted to Brinell hardness values and Vice versa. The test surface does not contain any defects, for example, such as scale, nicks or dirt. All defects were removed with sandpaper. During processing, the surface was not heated above $100^{\circ} \mathrm{C}$.

\section{CONCLUSION}

Soft steel and non-ferrous alloys were studied using Brinell and Rockwell methods. The results obtained were compared with a table for translating the hardness values.

The essence of the Brinell method is that a hard alloy ball under the action of a force that was applied perpendicular to the surface of the sample, for some time was pressed into the material, the sample. The hardness value in this case was determined based on the obtained measurements of the diameter of the print after removing the applied forces.

Similar results of measuring the hardness of the test material for different measurements of balls are obtained only if the ratio of force to the squares of the diameters of the balls remain the same.

The essence of the Rockwell method is to embed an indenter in a solid (test sample). At the same time, the depth of the print was measured during the study. A hard alloy ball and a diamond cone were used as the indenter.

\section{REFERENCES}

1. J.T. Bakirov, A.A. Ainabekova, U. M. Dyikanbaeva Heat treatment and mechanical tests. Methodical instructions for laboratory work on materials science for students of 
Olga I. Vaganova et al., International Journal of Emerging Trends in Engineering Research, 8(9), September 2020, 5651 - 5654

mechanical engineering specialties, B.:IC "Teknik", 2011. - $36 \mathrm{p}$.

2. S. G. Grigoriev, V. A., Shabunina, Ju. M. Tsarapkina, N. V. Dunaeva. Electronic library system as a means of self-development of students of digital generation Z (on the example of studying the course "Basics of the counselor activity"). Scientific and technical librarie, No. 7. Pp. 78-99. 29. 2019.

3. O. A. Andrienko. Network educational technologies and their use when working with students. Humanitarian Balkan Research 2019, 1(3), 5-7. 2019.

4. N.S. Abramova, O.I. Vaganova, L.I. Kutepova, Development of educational and methodological support in the context of the implementation of content and communication technologies. Baltiyskiygumanitarnyyzhurnal. Baltic Humanitarian Journal, 7, no. 2 (23), 181-184. 2018.

5. M.N. Bulaeva, O.I. Vaganova, M.N. Gladkova. Activity technologies in a professional educational institution.Baltiyskiygumanitarnyyzhurnal. Baltic Humanitarian Journal), 7, no. 3 (24), 167-170. 2018.

6. Z. V. Smirnova, O.I. Vaganova, O.T. Cherney, E.V. Romanovskaya, N.S. Andryashina, D.S. Toshin, The organization of emergency and dispatching servicing of an apartment house. International Journal of Innovative Technology and Exploring Engineering 8(9), $2019 . \quad$ c. $\quad 1477-\quad 1480$ https://doi.org/10.35940/ijitee.I8194.078919

7. Z. V. Smirnova, M.V. Mukhina, O.V. Katkova, M.L. Gruzdeva, O.T. Chernei, Network Interaction as a Factor of Professional Qualities' Development of Service Workers. Lecture Notes in Networks and Systems, 87, pp. 698-704. International Journal of Innovative Technology and Exploring Engineering. https://doi.org/10.1007/978-3-030-29586-8_81

8. G. T. Klinkov The specificity of manifestation of pedagogical communication as a special construct. Scientific Vector of the Balkans, 1, 51-52, 2018.

9. G.V. Klevtsov. Fractodiagnostics of the destruction of metallic materials and structures: textbook. allowance / G.V. Klevtsov [et al.]. - M.: MI-CC, 2007, pp. 264.

10. A. A. Sukhikh, T. M., Makhneva, V. B. Dement'evAustenite in nanostructured maraging steel, Inorganic Materials: Applied Research, vol. 10, no. 4, pp. 966-973. , 2019.

11. K. Yu. Boyko, A.V. Skripkina and K.Yu. Smartly. The use of syllabus funds in the technology of time management of self-educational activities of bachelors. Multilevel system of continuous professional education in the socio-cultural sphere: problems of continuity and integration, 73-78. 2019.

12. I. F. Filchenkova, Educational management of innovative activity of teachers as an object of pedagogical research.VestnikMininskogouniversiteta(Vestnik of Minin University), 2019. 7 (4), 3. (in Russ.).2019.

13. Z. V. Smirnova, A.A. Rudenko, O.I. Vaganova, O.T. Cherney, D.S. Mokerov, E.A. Semakhin, The research of carbon construction steel at laser alloying. International
Journal of Innovative Technology and Exploring Engineering. 2019

14. C. Santhosh, K. Hari Kishore, G. Pavani Lakshmi, G. Kushwanth, P. Rama Krishna Dharma, Teja, R. S. Ernest Ravindran, S. V. Cheerala, M. R. Kumar. Detection of Heavy Metal Ions using Star-Shaped Microfluidic Channel. International Journal of Emerging Trends in Engineering Research, 7, No. 12. 2019.

15. A. Zakaria, M. S. N. Ibrahi, Experimental Evaluation of Multiple Savonius Turbines in Oblique and Cluster Configuration, International Journal of Emerging Trends in Engineering Research, 7, No. 12. 2019.

16. Yu. P. Egorov, Yu.M. Lozinsky, E.I. Marr Laboratory practice materials science for students, students in the field of "Mechanical Engineering", 2015, pp. 34.

17. A.V. Kirjukhin, O. O. Milman, A. V. Ptakhin, V. D. Kuprjashov, Efficiency of Schemes of Active Broadband Damping of Vibration Forces Transmitted by Vibration Insulation to the Foundation, International Journal of Emerging Trends in Engineering Research, 7, No. 12. 2019.

18. J. T. Bakirov, A. A. AinabekovaKylash, U. M. Dyikanbaeva. Heat treatment and mechanical testing. Guidelines for laboratory work in materials science for engineering students specialties. KSTU named after I. Razzakov; comp.: Zh. T. Bakirov, A. A. ainabekova, U. M. dyykanbayeva. - B.: IC "Teknik", - 36 p. 2011.

19. V. E. Gordienko, E. G. Gordienko, S. A. Stepanov, Yu. V. Knyshev, A. P. Orlov, L. I. Zhigar. Technology of construction materials: textbook. manual: laboratory practice.Spbgasu. - SPb. Part I. material Science. - 64 p. 2009. 